feel justified in removing the larynx, but he thought an exploratory thyrotomy quite justifiable.

Dr. Dendas Grant said there was no evidence of tuberculosis in the chest and sputum. The man had not been put upon iodide of potassium, but there was no history of syphilis. Was it a case in which one should remove a piece for examination, or do an exploratory thyrotomy? If it was malignant, and any operation was to be done, the sooner the better. That was the position of the case.

\title{
PROCEEDINGS OF THE SOCIETY OF GERMAN SCIENTISTS AND PHYSICIANS.
}

\author{
Meeting at Aix-la-Chapelle. \\ Conjoint Sections for Diseases of the Ear and Throat.
}

$$
\text { President, Dr. Schuithuisen. }
$$

THF following papers were read:

Tortiary Syphilis of the Tongue, with Demonstration of Ihotographs and I'atient. Shown by Dr. Lreven (Aix-la-Chapelle).

The patient shown, although the disease was completely healed, presented on his tongue the following tertiary forms of late syphilis: (1) Glossitis gummosa circumscripta profunda. (2) Glossitis sclerogummosa profunda. (3) Glossitis sclerogummosa superficialis.

The patient was particularly interesting, as he had a peculiar idiosyncrasy towards potassium iodide. The severe tongue lesions improved under long-continued energetic inunction, but tended to recur some weeks after the mercury was stopped. If a preparation of iodide, however, was prescribed, there resulted in two or three days a deep ulcer on each gumma.

Dr. Lieven thought that there was an excessive hyperæmia present, which instead of causing absorption of the gumma, produced inflammation and tissue necrosis. He, therefore, considered the condition an increase of the ordinary hyperæmia so necessary for the absorption of the new growth. The patient had been free from recurrence for a year; the cure was effected by decoctum sarsaparillæ.

Dr. Hopuann (Cologne) had seen a similar case of syphilis of the tongue, which he described as glossitis hypertrophicans 
papillaris. The tongue was covered from front to back with fungiform papillæ.

Ierenrial Stomatitis. Shown by Dr. Lieven (Aix-la-Chapelle).

The author said that the tartar of the teeth most frequently caused localized stomatitis. Saliva containing mercury is quite unimportant in the causation of stomatitis, and he considered the salivation, as a rule, was produced secondarily to the inflamed mucous membrane. Stomatitis, he considered, could always be aroided, at least in severe forms, by the modern method of treatment. The only method by which this cannot with certainty be achieved is the injection of insoluble mercurial salts, especially of gray oil.* He prefers salicylate of mercury to other preparations. In conclusion, he quoted the history of a man with severe stomatitis, who had so profuse a hæmorrhage from the gums of his incisor teeth that his friends thought the blood must have come from the stomach.

Iermial Appearances in the Throat. Shown by Dr. SchmitHCINEN (Aix-la-Chapelle).

The speaker regretted that so little was known of the effects of mercury on the throat compared with mercurial stomatitis, which is one of the best known mercurial lesions. The difficulty of examination and the relative rarity of the condition explains this want of knowledge. The signs of chronic mercurial poisoning of the throat begin at the base of the tongue, between the tubercles of the mucous glands and the lingual tonsil. The affected parts are characterized at first by dark smooth spots, which soon become white, and later grayish-yellow. The spots occur almost always before similar appearances in the mouth. He considered the diagnosis very difficult, especially the differential diagnosis from stphilitic papules. They are certainly rare in the lower part of the pharmx. A further differential point is brought out by the continued use of mercury. The mercurial lesion becomes worse, the papules heal.

1). Hopmann (Cologne) had never seen typical mercurial lesions of the pharyns by themselves, but frequently along with lesions of the tongue and cheek.

\footnotetext{
* Gray oil. Oleum cinereum, an ointment made by triturating mercury to extinction with oil or liquid paraffin, varying in the amount of mercury from 1 to ::3 per cent. Oleum cinereum fortius, a preparation made by shaking together :30 parts of lanolin (dissolved in from 100 to 200 of chloroform) with 60 oi mereury, triturating until all the chloroform has evaporated and the mercury is completely divided, and adding an equal amount of olive-oil. Pr.. rit the Amer. Pharm Assoc.. xxxvii., p. 385 . (W. J. H.)
} 
Dr. Fischenich (Wiesbaden) thought that little was yet known of the nature of mercurial stomatitis, in spite of its long-continued study ; in one case, although the patient had only some fragments of his teeth in very bad condition left, yet every symptom of mercurial inflammation was absent.

Vibration Massage of the Upper Respiratory Tract by Means of Instruments. Demonstration on Patients. By Dr. Braun (Trieste).

In addition to an exhaustive discussion on the indications for the treatment, the paper dwelt largely on the methods which had been used by Dr. Braun for several years.

The Treatment of Typical Naso-pharyngeal Polypi, with Exhilition of Cases that had been (operated on. Shown by Dr. Schmiтni:Isex (Aix-la-Chapelle).

The operation is as follows: The growth is enclosed within the snare as high up as possible, then the snare is allowed to work by electrolysis for twenty-five minutes, the same snare is then connected with the galvano-cautery. The tumour is divided by the hot snare with hardly any hæmorrhage. Any remains of the tumour which may still impede breathing are destroyed by electrolysis; what is left over disappears of itself. Such polypi are peculiar phenomena of puberty, and always vanish spontaneously with increasing age.

Dr. Hopuann (Cologne) was of the opinion that a major operation is not required, and agreed with Dr. Schmithuisen that one can, and should, always operate by the natural openings. Dr. Hopmann draws the soft palate forward with a special instrument constructed for that purpose, and removes at one sitting by the aid of chloroform the whole growth with scissors and raspatory. There is severe hæmorrhage in the rapidly-performed operation, which is easily controlled by pressure. He considers his method the quickest, and to be recommended on these grounds, that after the operation is finished, the hæmorrhage which threatened the life of the patient is at once put a stop to.

Dr. Schmithuisen holds that the hæmorrhage is caused by obstruction, when the tumour is compressed in the narrow nasopharynx. It ceases after removal of a small piece of the growth. As soon as the snare is loosened, and the return of the venous blood is facilitated, the hæmorrhage ends.

Syphilitic Necrosis of the Nasal Floor. Shown by Dr. ScnмiтHUISEN (Aix-la-Chapelle).

In cases where there are large and firmly adherent necroses of the nasal floor, Dr. Schmithuisen bores holes into the dead bone. 
He can thus always easily remove the dead bone, as by this method its connections with the surrounding healthy bone are loosened.

Treatment of Syphilitic Necrosis of the Hard Palate. Shown by Dr. Lieven (Aix-la-Chapelle).

Dr. Lieven distinguishes on the roof of the mouth a primary gumma and a secondary form due to extension from the nose. Both affect the region of the raphe on the roof of the mouth. The second form is the more important, as it almost without exception causes perforation; while by the other, originating on the roof of the mouth, only a lamella of bone is separated. For the removal of sequestra which are firmly adherent, he bores into the bone and loosens it with a hook. By shaking twice daily demarcation occurs in eight to fourteen days, and it can then be removed. He cautions against too early use of an artificial plate, as this after a short time does not fit, owing to cicatricial contraction. He advises the application of a plug of cotton-wool to overcome the discomfort; two months after the resulting cicatrization a plate can be made, and six months later operative closure, provided there has been without anti-specific treatment no relapse in this time.

Leucoplasia of the Mouth, with Exhibition of Patients. Shown by Dr. Lieven (Aix-la-Chapelle).

Dr. Lieven brought forward the following theory of smoker's cheek (Raucherwange), by which he would explain the peculiar appearance. When the mouth is open, only the visible mucous membrane of the cheek is coloured; that covered by the teeth is always normal. At each draw of the pipe or cigar the mucous membrane is drawn inwards between the rows of teeth, and there flows into the mucous membrane each time a quantity of blood to take the place of the air removed by aspiration. Chronic hyperæmia, catarrh and epithelial hyperplasia are the result of such deleterious influence, the further stage of which is the resulting leucoplasia.

A Case of Bronchitis Fibrinosa. Shown by Dr. Hopmann (Dresden).

He demonstrated some preparations under the microscope, which showed the fibrinous character with unusual distinctness in the expectorated coagula of fibrin; the latter formed a completely united cast of the smaller bronchi. 
Bacteriology of Sinus Thrombosis. Shown by Dr. Еıсннон (Coburg).

He found in two cases of thrombosis, in the contents of the sinus and vena jugularis, also in the pulmonary metastasis, in addition to staphylococci and diplococci, bacilli, which proved by culture and animal experiment to be those of malignant cedema. Examination of part of the jugular removed at the operation showed in places hæmorrhagic cedema of its walls. He emphasizes specially the virulence of mixed infection with aerobic and anaerobic organisms.

Syphilis of the Nasu-pharynx. Shown by Dr. Fishenich (Wies. baden).

The speaker described this form at the outset as a localized form of syphilis, which was still unknown to specialists even in the more recent publications. The existence of an isolated nasopharyngeal syphilis without any other indication of the disease was not recognised. He then described some cases from his own practice.

Dr. Horuann (Cologne) did not agree that syphilis of the nasopharynx was a disease not well known by specialists. On the contrary, the works of Seifert, Gerber and numerous other authors show that this disease has latterly been thoroughly studied. The large number of publications have made this disease quite well known.

Dr. Lieven (Aix-la-Chapelle) described the danger of hitmorrhage following a tertiary lesion in the naso-pharynx. There have been several cases of this described, in which, after the loss of a necrotic part of a cervical vertebra, fatal or dangerous hrmorrhage has occurred. This has been observed both from the carotid and vertebral artery.

Dr. Schurtuusen (Aix-la-Chapelle) has found the sphenoidal sinus several times affected in syphilis of the naso-pharynx. 